\title{
Unexpected patterns of chironomid larval size in an extreme environment: a highly glaciated, alpine stream
}

\author{
Stefan Andreas Schütz $\mathbb{D} \cdot$ Leopold Füreder
}

Received: 5 October 2017 / Revised: 22 February 2018/Accepted: 3 March 2018/Published online: 16 March 2018

(C) The Author(s) 2018

\begin{abstract}
In this article, we report on the development and growth of alpine chironomid species in a highly glaciated headwater, using biometrical analyses. Glacially influenced alpine streams are characterized by year-round harsh environmental conditions. Only a few, highly adapted benthic insects, mainly chironomid larvae (genus Diamesa) live in these extreme conditions. Although several studies have shown patterns in ecosystem structure and function in alpine streams, cause-effect relationships of abiotic components on aquatic insects' life strategies are still unknown. Sampling was performed at Schlatenbach, a river draining the Schlatenkees (Hohe Tauern NP, Austria), at three sites and on six occasions from August to October 2015. Semi-quantitatively sampled Diamesa cinerella (Meigen 1835) and Diamesa steinboecki (Goetghebuer 1933) larvae were biometrically analysed, and they showed differences in larval size and biovolume with higher values close to the glacier.
\end{abstract}

Handling editor: Eric Larson

Electronic supplementary material The online version of this article (https://doi.org/10.1007/s10750-018-3579-y) contains supplementary material, which is available to authorized users.

S. A. Schütz $(\bowtie) \cdot$ L. Füreder

River and Conservation Research, Institute of Ecology,

Leopold-Franzens University of Innsbruck,

Technikerstraße 25, 6020 Innsbruck, Austria

e-mail: stefan.schuetz@student.uibk.ac.at
Considering the decreasing water temperatures but increasing benthic organic matter towards the glacier, food availability seems to play a crucial role for larval size in highly glaciated alpine headwaters. This is the first study to show that harsh conditions in these environments (low temperatures, high turbidity and flow dynamics) may exclude many taxa, but favour other, highly adapted species, when their essential needs (food quality and quantity) are guaranteed.

Keywords Life cycle - Diamesa - Biometric analyses - Glacier retreat $\cdot$ Chironomidae

\section{Introduction}

Habitats with harsh environmental conditions are spread all over the world ranging from hot springs, dry desserts to high altitude mountaintops (Füreder, 1999; Jacobsen \& Dangles, 2012). Streams in the alpine zone are among the most extreme freshwater ecosystems, characterized by harsh environmental conditions like high solar radiation, year-round low air and water temperatures, scarce vegetation, short snow free season and often draining glaciers in the catchments (Milner \& Petts, 1994; Ward, 1994; LodsCrozet et al., 2001; Füreder et al., 2005; Brown et al., 2015). In the future, climate change effects intensify the already rough abiotic conditions by accelerated 
glacier melt, leading to enhanced discharge with lower water temperatures, increased turbidity, higher abrasion, lower habitat stability, little algal growth, and hence decreased nutrient retention compared to the current situation (Brown et al., 2007, 2010; Finn et al., 2010; Robinson et al., 2014).

Glacier recession will also create new ice-free habitats in glacier-fed (kryal, sensu Steffan, 1971) streams (Robinson et al., 2014), representing a refuge for alpine benthic invertebrates in times of climate change (Brittain \& Milner, 2001; Finn et al., 2010). The larval community of these aquatic insects, dominated by chironomids (Steffan, 1971), has to face and master the stressful living conditions in order to successfully colonize and inhabit the uppermost stream reaches of alpine rivers. Former studies pointed out that highly adapted species, mainly from the chironomid genus Diamesa (Milner \& Petts, 1994; Brittain et al., 2001; Robinson et al., 2001) withstand the tough abiotic conditions and inhabit kryal streams directly from the glacier snout, partially reaching high individual numbers at suited microhabitats (Finn et al., 2010; Robinson et al., 2014; Rossaro et al., 2016). Recently, significant knowledge concerning species habitat preferences and harshness resistance has been gained (e.g., Niedrist \& Füreder, 2016), identifying water temperature and nutrient availability as the major driving forces for species appearance and benthic community composition (e.g., Milner \& Petts, 1994; Brittain et al., 2001; Finn et al., 2010; Marziali \& Rossaro, 2013).

Chironomids are holometabolic insects following a defined life cycle pattern. The larva is hatching from the egg, goes through four larval instars (L1, L2, L3 and L4) to a pupa stage, and finally emerges as an adult, terrestrial insect (Walker, 1987). Despite this relatively simple development, chironomid growth and life cycles in the colder climatic zones have hardly been investigated (but see Nolte \& Hoffmann, 1992; Hannesdottir et al., 2012). This is particularly true for high alpine species. Most studies so far concentrated on the benthic larval life of Ephemeroptera, Plecoptera and Trichoptera (e.g., Brittain, 1983; Dobrin \& Gibberson, 2003; Finn \& Poff, 2008; Resh \& Rosenberg, 2010; Beracko et al., 2016; Carlos \& Puliafico, 2016).

Some of these former studies revealed correlations of changing environmental conditions and the benthic larval growth in temperate streams below the tree line.
In other studies, water temperature and/or nutrient availability seemed to be the main driving forces shifting benthic larval life (Erba et al., 2003; Reynolds \& Benke, 2005; Sand \& Brittain, 2009). Quite a number of surveys in the past were set up as laboratory experiments to manipulate the most important abiotic factors and strictly follow the nymphal reactions on the altered environmental conditions (e.g., Mackey, 1977; Sweeney et al., 1986; Corkum \& Hanes, 1991; Stanko-Mishic et al., 1999; Hooper et al., 2003). Thereby, increased water temperature or nutrient availability, compared to the control conditions, partially led to improved larval growth and increased biovolume (e.g., Sweeney et al., 1986; Reynolds \& Benke, 2005; Wagner, 2005). These laboratory experiments were a crucial step to understand the principal mechanisms of benthic larval growth and development in temperate and low alpine streams.

By simulating changing environmental conditions on the benthic larval life, relevant interactions of the naturally predominant abiotic conditions might be missed, leading to misinterpretations of current processes, future changes and adaptions of benthic species to changing environmental conditions (Sweeney et al., 1986). Moreover, the complex and harsh abiotic characteristics of a highly glaciated stream are hardly reproducible in laboratory experiments. Therefore, knowledge about the larval growth dynamics, development histories, age structure, retention time and colonization patterns of the benthic community in highly glaciated stream reaches is still scarce (Danks, 2007; Elliot, 2013). Only by following the benthic development in the natural, kryal stream habitats, the complex interactions of benthic key species with the entity of occurring environmental factors can be investigated and the main abiotic driving forces, influencing benthic larval life will be displayed.

Rivers, from their origin to the mouth, are a continuum with changes in the uppermost reaches affecting the whole ecosystem downstream (e.g., Vannote et al., 1980; Füreder, 2007). High alpine benthic larvae are an important link in stream food webs, as they initially take up and store allochthonous and autochthonous organic material in the stream (Beracko et al., 2016; Niedrist \& Füreder, 2017). Knowing the species' reactions on specific abiotic conditions and key factors positively affecting larval size, knowledge about the benthic larval growth and development will be gained. Moreover, increased 
larval size walks along with an extended assimilation of biomass in the stream food chain, fertilizing the whole freshwater ecosystem (e.g., Brittain, 1983; Sweeney et al., 1986; Corkum \& Hanes, 1991).

The aim of the present study was to investigate the larval growth of alpine aquatic invertebrate species subjected to small-scale abiotic alterations in kryal stream habitats, in close vicinity to the glacier. By regularly sampling the benthic community and key environmental factors at three recently constituted stream stretches, towards the end of the snow free season, representing the most important time of the year for high alpine benthic invertebrate growth due to reduced discharge, higher water temperatures, and enhanced nutrient availability (Uehlinger et al., 2010), larval size patterns of high alpine chironomid species were followed for the first time. Former studies have shown that water temperature is the essential factor, influencing benthic larval growth with a threshold of $2.3^{\circ} \mathrm{C}$ for chironomid larvae (Huryn \& Wallace, 1986). Glacier-fed streams are often characterized by even lower temperatures, raising the question if and how big larvae can grow under such harsh conditions and how long they need to complete their aquatic life stages. Along a temperature gradient bellow the hitherto valid limit, we follow the benthic larval growth of highly adapted chironomid key species in a kryal headwater. Furthermore, we test whether the insects are able to effectively use an increased availability of nutrition and if food availability plays a more important role for larval growth than previously thought. Morphometric measurement tools allowed us to visualize the benthic larval growth and development over time and, in a second step, to elucidate the interdependency with environmental conditions.

\section{Materials and methods}

Study area and site selection

The kryal Schlatenbach (i.e., section close to the glacial snout), draining the Schlatenkees glacier in the Innergschlöß valley, East Tyrol, Austria, was chosen for fieldwork, as a rapid glacier retreat has been observed over the recent years. The stream is located in the Hohe Tauern National Park and therefore free of direct human impacts like damming, pollution and nutrient enrichment. Sampling took place six times in the alpine summer and autumn (August-October) 2015 covering most of the snow free season. At each expedition, three stream stretches were sampled. Site 1 was still covered by the glacier in September 2014. According to the official annual glacial report of the Austrian Alpine Club, the Schlatenkees glacier snout retreated for 60.3 metres in 2015 (https://www. alpenverein.at/portal/news/aktuelle_news/2016/2016_ 04_08_gletscherbericht.php; downloaded on 22 December 2017), whereby site 1 got ice-free during spring/summer 2015, only some months before the initial sampling. Site 2 was ice-free since late 2012 and site 3 since late 2009 (Fig. 1). Positions of glacier snouts in 2009, 2012 and 2015 were taken from the Tyrolean geographical information system (https:// portal.tirol.gv.at).

\section{Benthic invertebrates}

Overall 54 semi-quantitative benthic samples, three replicates at each sampling site per expedition, were taken using a $0.09 \mathrm{~m}^{2}$ Surber Sampler with $100-\mu \mathrm{m}$ sized net. Sampling was restricted to permanently overflown stream stretches reflecting the predominant habitat characteristic and grain size. Each benthic sample was immediately fixed in $75 \%$ Ethanol. In the laboratory, larvae were handpicked and identified to species level using available keys (Schmid, 1993; Janecek, 1998; Rossaro \& Lencioni, 2015a, b) under a microscope. Due to their frequent and continuous abundance, larvae of Diamesa cinerella (Meigen 1835) and Diamesa steinboecki (Goetghebuer 1933) were used for growth analysis. Chironomid pupae were determined to species level following Langton (1991).

Morphometric measurements and growth rate

A set of 19 landmarks was defined to morphometrically analyse each individual organism. Larval length was measured from the anal setae to the beginning of the head capsule (landmarks 1-13) plus the length of the head capsule, from the beginning of the capsule to the front end of the antennal-base (landmarks 16-17, Fig. 2). Landmarks 18-19 were set to the widest point of the head capsule, determining the head capsule width (Fig. 2). As the fourth body segment reflects the shape of chironomid larvae (Nolte, 1990), the length 
Fig. 1 Map of sampling sites, glacial retreat and catchment shape. Altitudes and positions of the glacier snout in 2009, 2012 and 2015 (written in italics) taken from the Tyrolean geographical information system (https://portal.tirol. gv.at). L. Füreder photographed the glacial position in September 2014
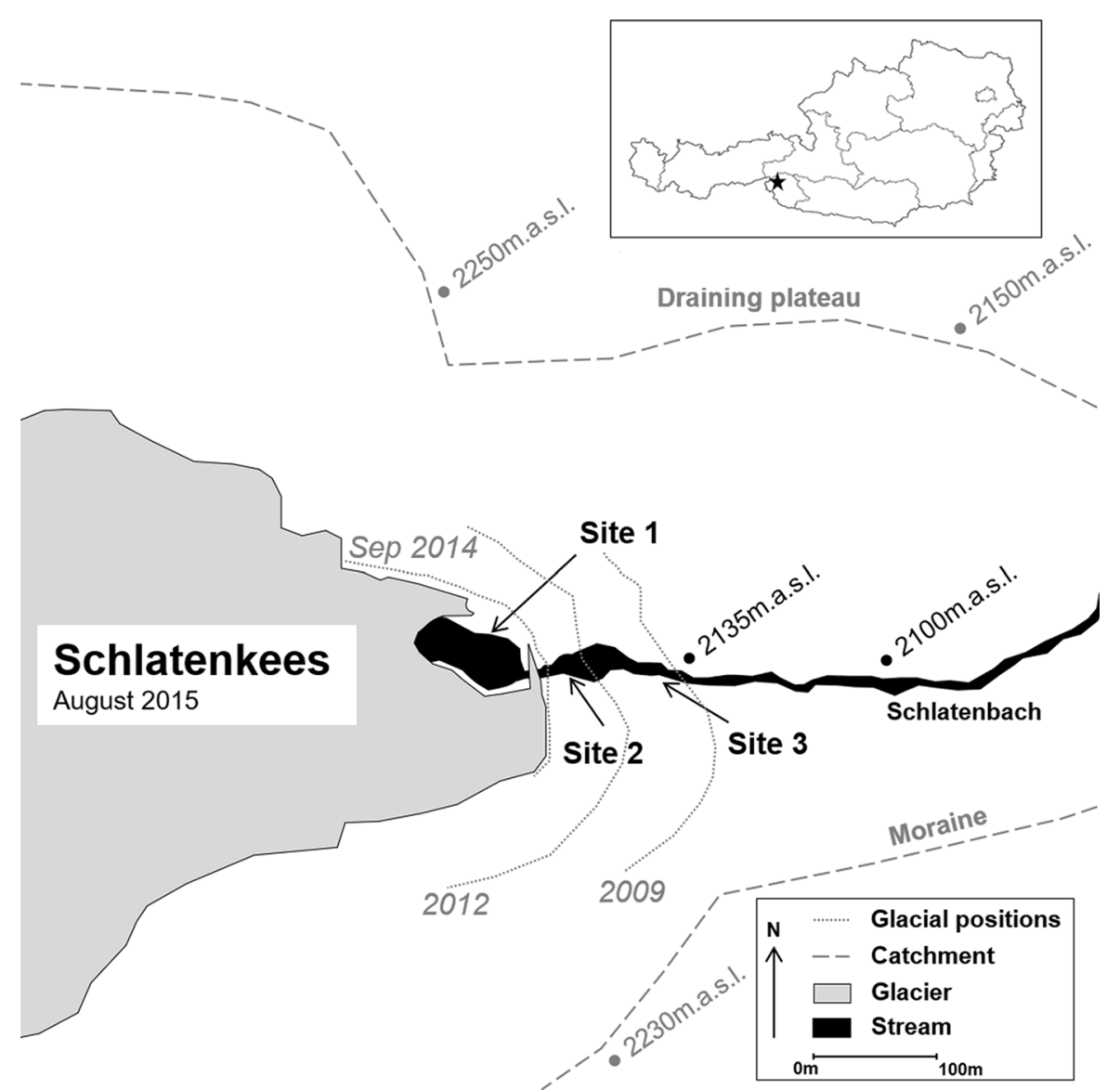

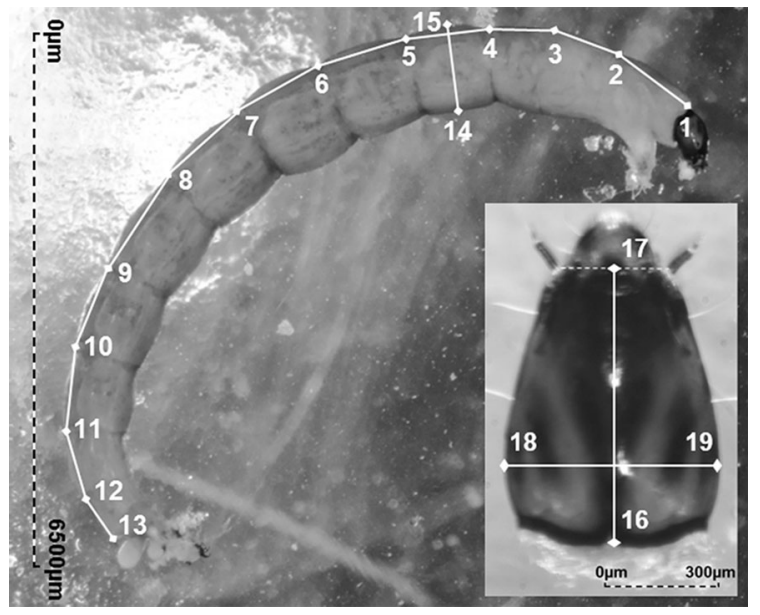

Fig. 2 Lateral view of Diamesa cinerella larva, dorsal view of Diamesa cinerella head and the position of the 19 landmarks used for morphometric measurements

(Landmarks 4-5) and width/height (landmarks 14-15) of the fourth segment were measured. Biovolume of each individual was calculated by multiplying the larval length with the volume of the fourth segment. For the measurements, each single larva was first photographed laterally, then the head capsule was cut off and photographed dorsally using a reflected light microscope with trinocular port, digital mirrorless camera (Pentax Q, attached to microscope with C-mount to Q-mount adapter) and known scale. For morphometric measurements, the program "Jens Rüdigs Makroaufmaßprogramm" (version 0.9.2; http://ruedig.de/tmp/messprogramm.htm) was used.

Linear regression proved to be the best model of curve fitting regression analysis, relating the mean larval length and mean larval volume to development days (see Supplementary Table 1). Therefore, growth rate was assumed to be linear and calculated as instantaneous, daily growth rate $(\mathrm{G})$ for length and volume, both species and all three sampling sites separately, following the equation $G=\left(M_{t}-M_{0}\right) / t$ (Romanovsky \& Polishchuck, 1982), where $\mathrm{M}_{\mathrm{t}}$ is the 
mean of the length/volume at the last sampling date, $\mathrm{M}_{0}$ is the mean of the length/volume at the first sampling date, and $t$ is the period of growth in days (development days; following Huryn \& Wallace, 1986).

\section{Habitat characterization}

Water temperature was measured in the late morning of each expedition using WTW multi-parameter portable meter at all three sites, within a few minutes in order to guarantee comparability. After removing all larvae from the semi-quantitative samples the remaining material was placed in aluminium dishes, dried at $60^{\circ} \mathrm{C}(24 \mathrm{~h})$, weighed, burned at $450^{\circ} \mathrm{C}(2 \mathrm{~h})$ and weighed again to estimate the content (dry weight) of organic matter. The amount of benthic organic material in the samples represents the availability of food for the inhabiting benthic larvae.

Data analyses

Mann-Whitney- $U$-tests compared the water temperatures and benthic organic materials at the three sampling sites across all sampling dates. A nonparametric test was required, as both measures were not normally distributed (even after $\log 10$ transformation). We related benthic organic material and individual numbers of benthic invertebrates with ANOVA. $\log 10$ transformation of the dependent variable was necessary to meet the model assumptions of normality and homogeneity. To follow larval development, the four larval instars of all Diamesa species found in the samples were visualized in frequency histograms of the head capsule width, with each peak representing an instar (following Daly, 1985). We compared the L4 larval head capsule width of Diamesa cinerella and Diamesa steinboecki at the three sampling sites with Mann-Whitney- $U$-tests. A nonparametric approach was used as $D$. cinerella data were not normally distributed (even after $\log 10$ transformation), and head capsule widths of $D$. steinboecki showed normality but were heteroscedastic (even after $\log 10$ transformation).

Four MANCOVAs were computed to check for the sampling site effects on the larval length and volume of each possible growth pattern and species, individually. Larval length and volume were treated as separate, dependent variables, sampling site as fixed factor and development days (period of growth in days) as covariate.

Statistical analyses were performed in IBM SPSS Statistics 23 and considered significant at $P<0.05$. Data showed normality with non-significant Kolmogorov-Smirnov test and homogeneity with nonsignificant Levene's test. Graphics were created in Microsoft Excel 2016 and SigmaPlot 13.0 (Systat).

\section{Results}

Abiotic conditions and chironomid densities

Water temperature increased with increasing distance from the glacier snout (Fig. 3; for mean values of each sampling see Supplementary Table 2), with site 1 being significantly colder than site $3(P=0.005)$. Organic matter decreased with increasing distance from the glacier (Fig. 3, for mean values of each sampling see Supplementary Table 2). Samples from site 1 had a significantly higher amount of organic material compared to site $2(P=0.003)$ and site 3 $(P<0.000)$. Site 2 was also characterized by a significantly higher amount of organic material compared to site $3(P=0.003)$. The organic matter at the three sampled sites generally increased during the sampling period. Algal mats of Hydrurus foetidus (Villars 1848), a Chrysophyceae, were covering the stones at site 1 throughout the sampling period. Samples from site 2 contained the algae from the fourth sampling occasion onwards and was present at site 3 on the last expedition (Fig. 3).Nutrient availability had no significant influence on the dispersal of chironomid larvae in the sampled stream $(P=0.293)$. The larvae did not preferably inhabit stream sections with high nutrition quantity, nor did they avoid low nutrient concentrations.

\section{Larval stages}

For the evaluation of the benthic larval growth and development, it is crucial to distinguish the four different larval stages (L1-L4) of each species. Sizefrequency histograms (Fig. 4) display the head width of the four larval stages of all Diamesa species in the samples (for means see Table 1). According to these classifications, the larval development during the sampling period can be followed for the two 
Fig. 3 Water temperature $\left[{ }^{\circ} \mathrm{C}\right]$, dots with lines drawn for a better visualization of the temperature trends, and benthic organic material dry weights [g] of the three sites for all six sampling dates; " $\mathrm{H}$ " indicates the presence of Hydrurus foetidus in the samples

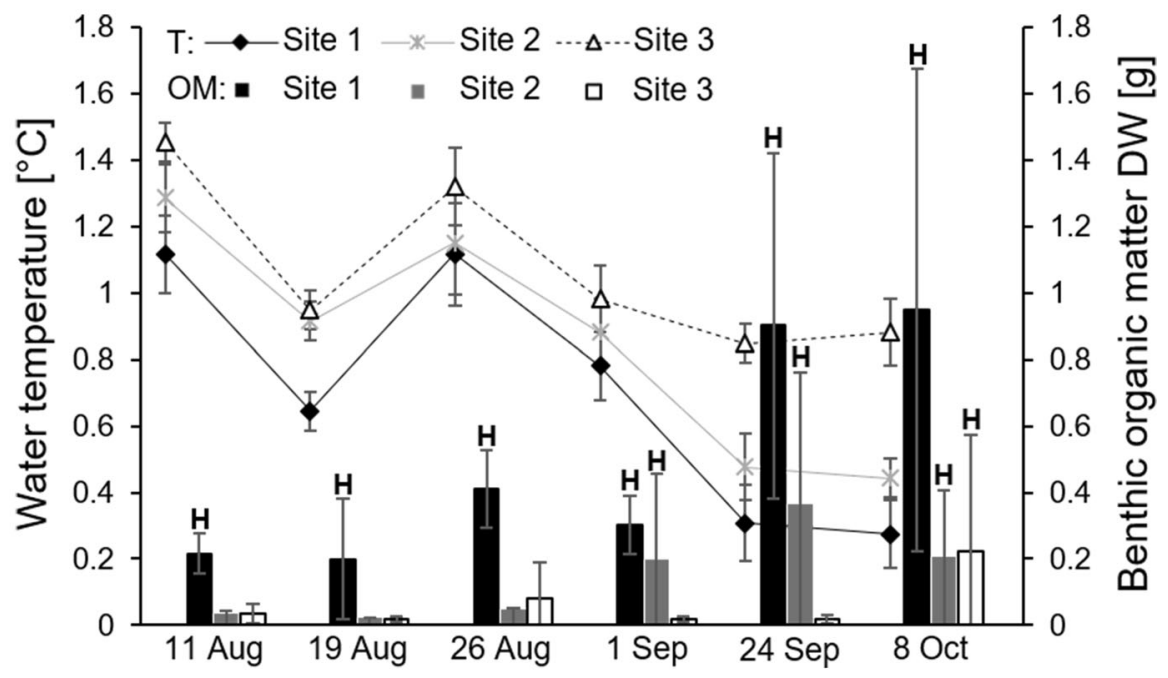

frequently present species Diamesa cinerella (Fig. 5) and Diamesa steinboecki (Fig. 6). The size-frequency diagrams (Figs. 5, 6) show that larval instar composition of both species hardly differed between the three sites throughout the sampling period. Towards October, the majority of larvae were in the final L4 larval stage. We want to highlight the presence of pupae of $D$. cinerella on the last two samplings at all three sites and of D. steinboecki at site 2, fifth sampling. These samples also partially contained L1 and L2 larvae of both species.

Head capsule width and larval size

To check for differences in larval size of $D$. cinerella and D. steinboecki, at first, the head capsule widths of the L4 larvae at the three sampling sites were compared. Head capsule width of D. cinerella L4 larvae decreased significantly with the increasing distance from the glacier (site 1 -site $2(P<0.000)$ and site 1 -ite $3(P<0.000))$. Head capsules at site 2 were also significantly bigger compared with site 3 $(P=0.001) \quad$ (site 1: mean $=444.2 \mu \mathrm{m} ;$ std $=42.5$ $\mu \mathrm{m}, n=259$; site $2:$ mean $=417.7 \mu \mathrm{m}$, std $=40.8$ $\mu \mathrm{m}, \mathrm{n}=330 ;$ site $3:$ mean $=401.3 \mu \mathrm{m}$, std $=36.7$ $\mu \mathrm{m}, n=85$; see Fig. 7). Comparison of head capsule width for D. steinboecki revealed the same trend of decreasing head capsule width with the increasing distance from the glacier ( site $1:$ mean $=358.9$, $\mathrm{std}=$ $37.1, n=31 ;$ site 2 : mean $=353.2$, std $=25.2$, $n=123$; site 3 : mean $=347.1$, std $=24.0, n=122$; see Fig. 7). We found statistically significant differences only between site 2 and site $3(P=0.049)$.

Based on the spatio-temporal distribution of larval stages during the sampling period (Figs. 5, 6), two patterns of larval growth are possible. The first is a slow larval growth, where the larvae need the complete sampling period to finish their development as L4 larvae. A significant sampling site effect on the larval length $(P<0.000)$ and larval volume $(P<0.000)$ of $D$. cinerella was evident. L4 larvae of this species proved to be longest and bulkiest at site 1 , close to the glacier, followed by site 2 and site 3 (Fig. 8a, b; for mean values see Supplementary Table 3, individual numbers are given in Supplementary Table 7). On the first sampling trip, no L4 $D$. steinboecki were present at site 3 . At the third sampling, no L4 larvae were in the samples from site 1 and site 3 . There was no significant sampling site effect on the slow larval growth of D. steinboecki. However, L4 larvae of D. steinboecki from site 1 and site 2 had the trend to be longer and bulkier than larvae from site 3 (Fig. 9a, b; for mean values see Supplementary Table 4 , individual numbers are given in Supplementary Table 8).

Another potential growth pattern is a quick development of the larvae from L2 on the first field trip, to L3 on the second expedition, and L4 larvae from the third sampling onwards. There was a significant sampling site effect on the fast development of $D$. cinerella larvae regarding larval volume $(P=0.013)$. There was, however, no significant sampling site effect on the larval length. L2 larvae hardly differ in 
Fig. 4 Frequency histograms of head capsule width $[\mu \mathrm{m}]$ for the four present Diamesa species joined for the three sites and all sampling dates, individual numbers in parentheses
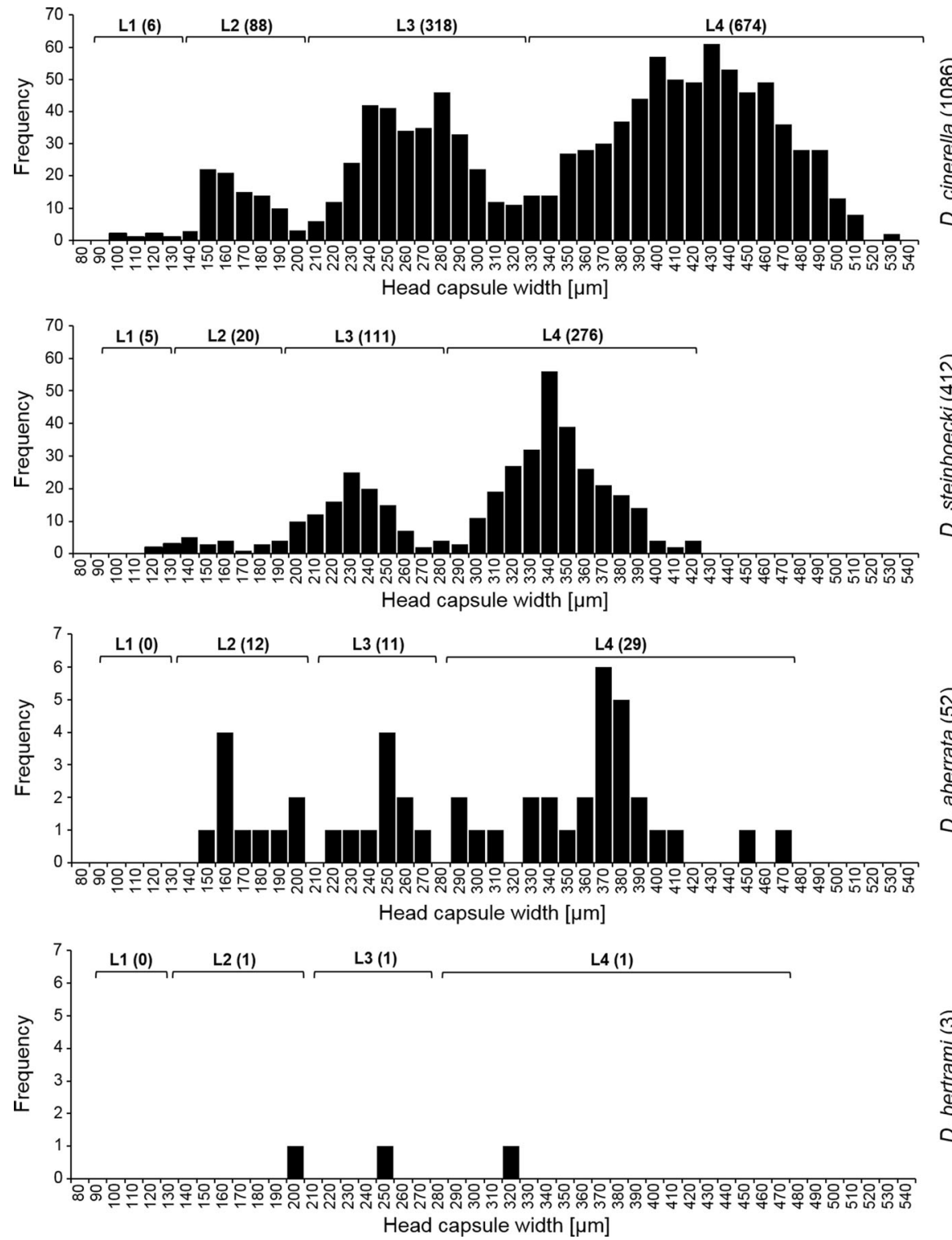

Table 1 Means and standard deviations of head capsule width $[\mu \mathrm{m}]$ for the four larval stages of all Diamesa species found in the samples

\begin{tabular}{lllll}
\hline Larval stages & L1 $[\mu \mathrm{m}]$ & L2 $[\mu \mathrm{m}]$ & L3 $[\mu \mathrm{m}]$ & L4 $[\mu \mathrm{m}]$ \\
\hline Diamesa cinerella & $117.4 \pm 11.9$ & $172.0 \pm 14.9$ & $269.9 \pm 26.5$ & $425.8 \pm 43.7$ \\
Diamesa steinboecki & $131.0 \pm 7.3$ & $167.9 \pm 20.4$ & $237.4 \pm 19.9$ & $351.1 \pm 26.5$ \\
Diamesa aberrata & - & $172.8 \pm 21.2$ & $250.3 \pm 16.1$ & $368.5 \pm 41.7$ \\
Diamesa bertrami & - & $208.7^{\mathrm{a}}$ & $257.8^{\mathrm{a}}$ & $322.2^{\mathrm{a}}$ \\
\hline
\end{tabular}

${ }^{\text {a If }} n<3$ single values are given

length and volume, whereas L3 and L4 larval length and volume decreased with increasing distance from the glacier (Fig. 8c, d; for means see Supplementary
Table 5, individual numbers are given in Supplementary Table 7). At site 1, no L2 D. steinboecki were present on the first sampling date. L4 larvae were 
Fig. 5 Larval-stage frequency distribution of Diamesa cinerella at the three sites during the sampling period; asterisk indicates the presence of pupae

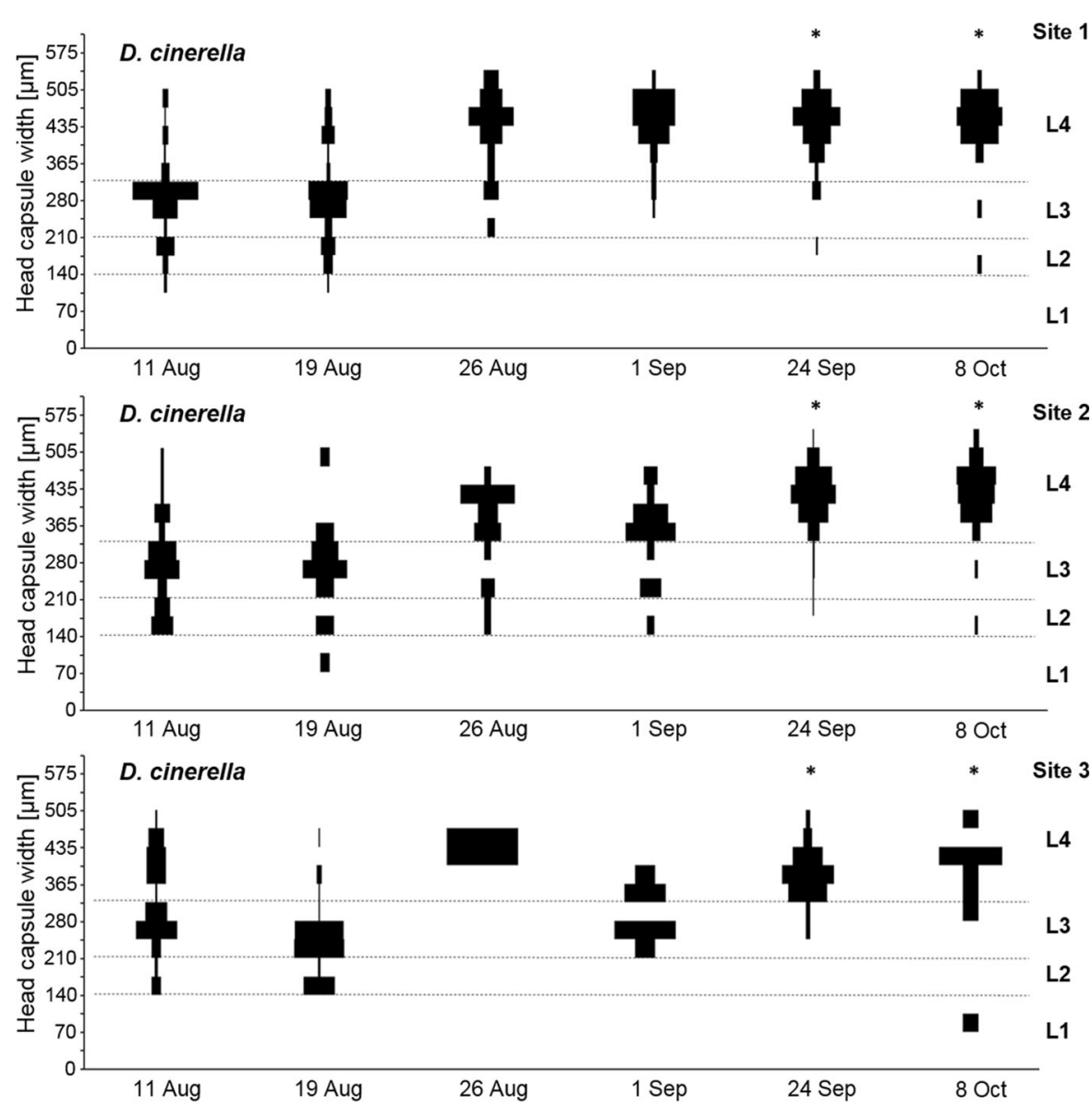

growing season. Growth rates of Diamesa cinerella were lowest at site 3. Larvae from site 1 had lower growth rates compared to site 2, as L4 larvae from the uppermost sampling site were longer and bulkier at the first sampling date compared to larvae from site 2 . For the fast development scenario, growth rates were again lowest at site 3 . For larval volume, rates at site 1 were the highest. Larvae from site 2 showed the highest gain in length. Growth rates of Diamesa steinboecki from site 2 were highest, followed by site 1 and 3 . This trend was found for larval length and volume at both development scenarios. For the fast development, growth rates for $D$. cinerella at site 3 and $D$. steinboecki at site 1 need to be discussed with care, as L2 larvae at the first sampling date are missing, leading to an underestimation of the growth rates.

Growth rates of the two observed species varied considerably between the sites (Table 2 and Figs. 8, 9). Concerning the slow development, differences in larval size became more distinct throughout the 
Fig. 6 Larval-stage frequency distribution of Diamesa steinboecki at the three sites during the sampling period; asterisk indicates the presence of pupae
Fig. 7 L4 head capsule width $[\mu \mathrm{m}]$ of Diamesa cinerella (left) and Diamesa steinboecki (right) at the three sites throughout the sampling period
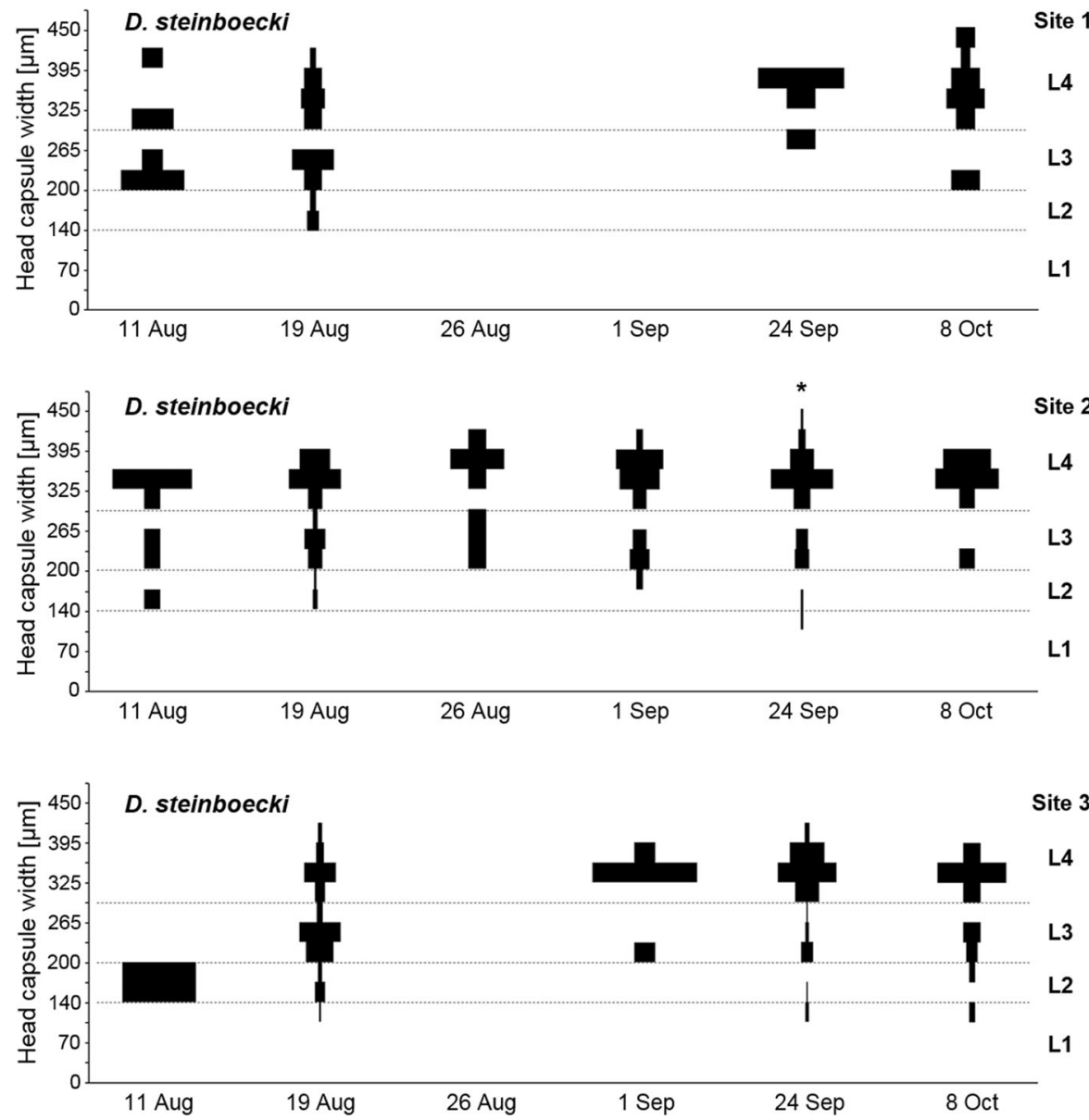

Diamesa cinerella

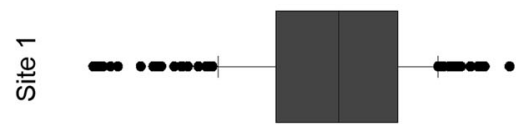

Diamesa steinboecki
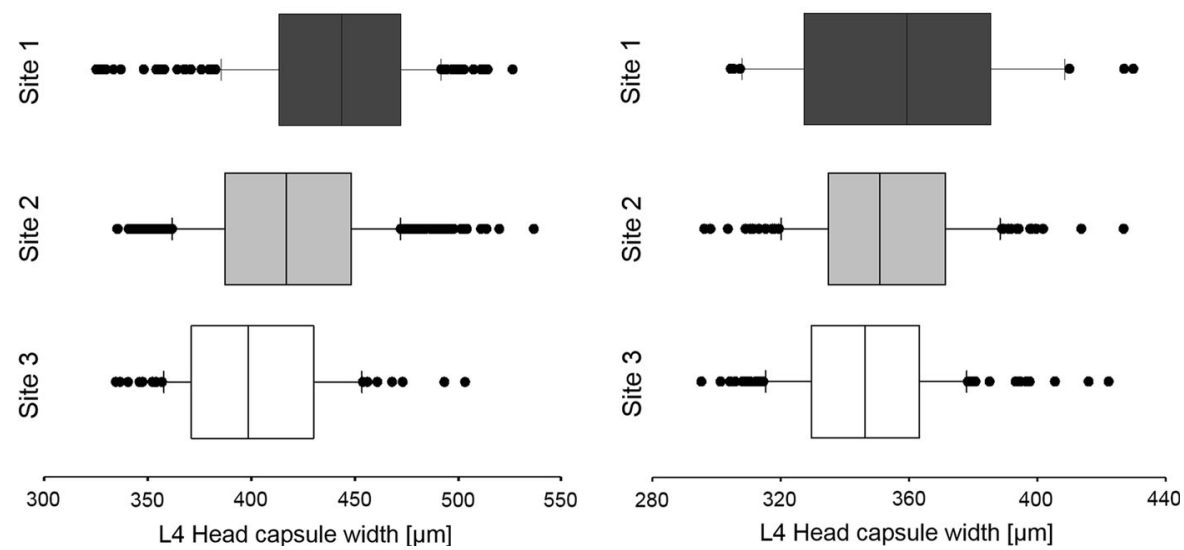

\section{Discussion}

Our study supports that although glacial headwaters are harsh environments, they can be highly productive for some invertebrate species. Water temperature and benthic organic matter (representing the nutrition for benthic invertebrates), obviously two of the most important drivers on larval growth and development, 

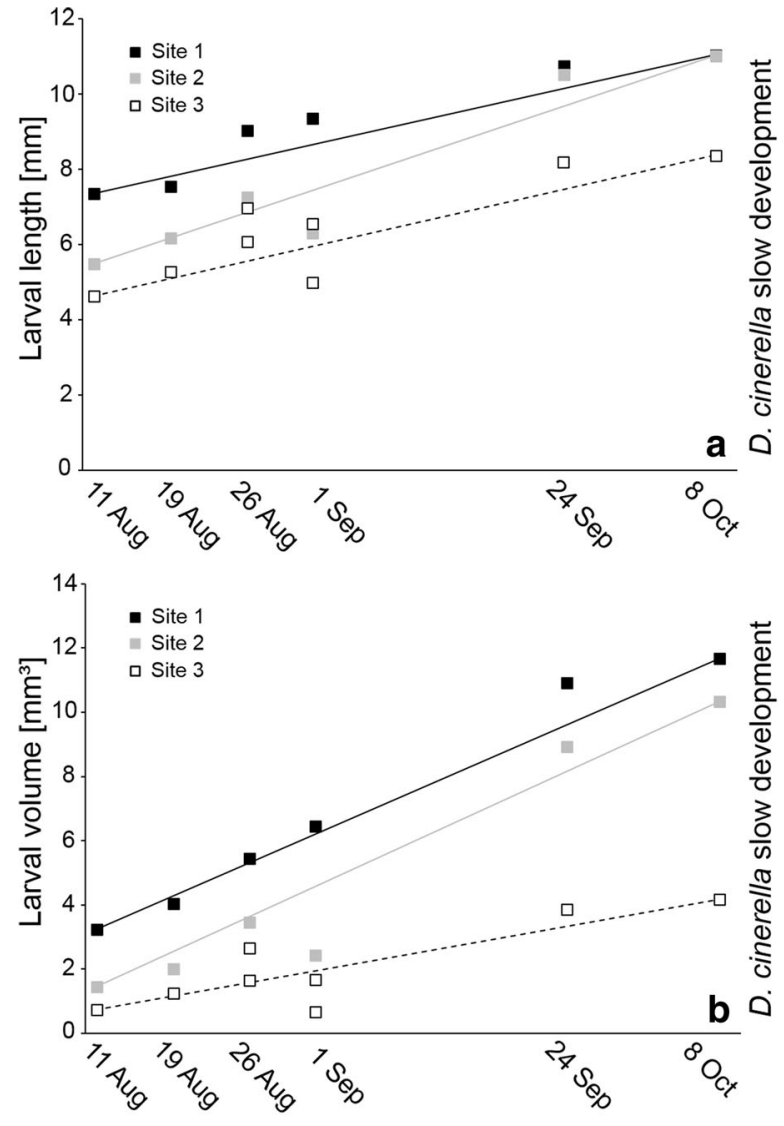

Fig. 8 Slow development of Diamesa cinerella on the left: means of larval length (a) and larval volume (b) with growth rates (site 1: solid black line, site 2: solid grey line, site 3: dashed black line). Fast development of Diamesa cinerella on the right:

were assumed to increase with increasing distance from the glacier. This was found for water temperature with a significant increase within roughly 100 metres of flow, equivalent to Uehlinger et al. (2003), who calculated a temperature rise of $0.005^{\circ} \mathrm{C}$ per metre flow length in a Swiss alpine glacial stream. Along with higher water temperatures, an enhanced content of benthic organic matter would have been obvious. Our results, however, showed the opposite. Accountable for the high amount of benthic organic matter at site 1 and partially at site 2 is Hydrurus foetidus, a Chrysophyceae, mainly colonizing glacially influenced headwaters (e.g., Robinson et al., 2015). The increase of periphyton biomass at site 2 and site 3 in September and October matches the findings of Uehlinger et al. (2010) where the authors predict an increase in algal biomass in autumn/winter due to the lowered air temperatures accompanied with less glacier melting.
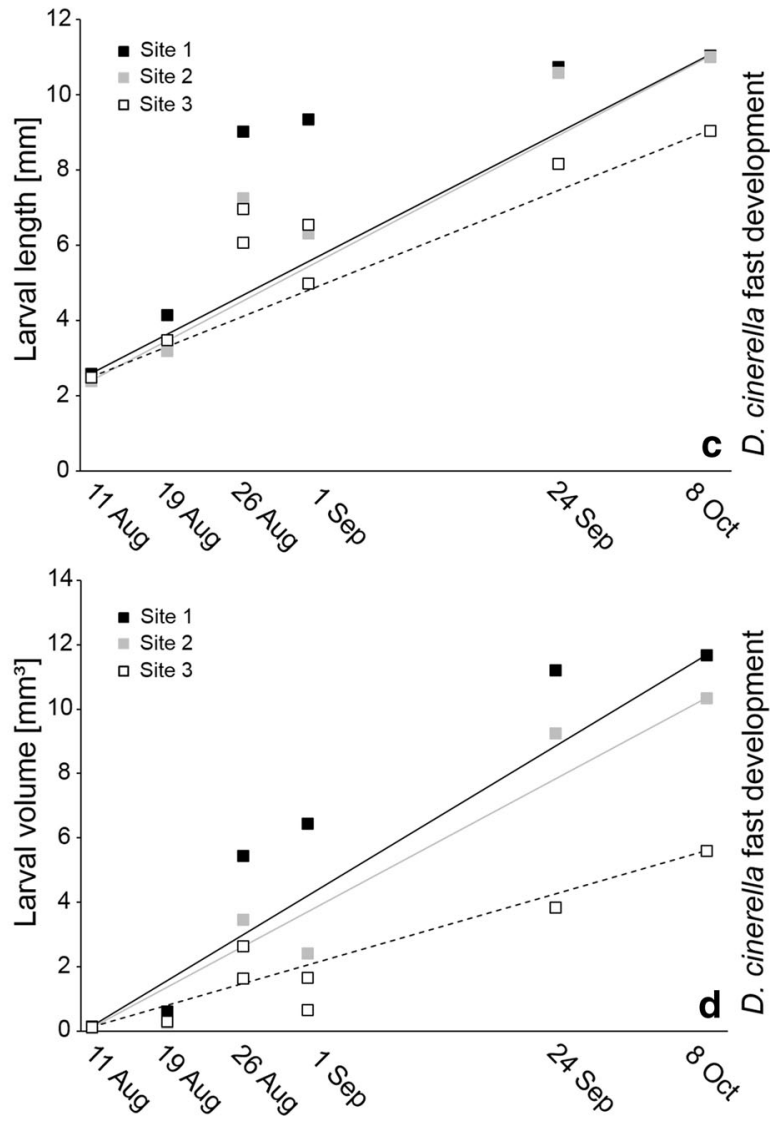

means of L2 (sampling 1), L3 (sampling 2) and L4 (sampling 3-6) of larval length (c) and larval volume (d) with growth rates (site 1: solid black line, site 2: solid grey line, site 3: dashed black line)

The high amounts of periphyton biomass at site 1 throughout the sampling period do not follow the known patterns. Total quantity of benthic organic matter at the three sites is, compared to the findings of Robinson et al. (2001), relatively low.

Hydrurus foetidus is both an important nutrient source (e.g., Niedrist \& Füreder, 2017) and habitat for chironomid species (Knownacka \& Knownacki, 1972). In the present study, periphyton biomass had no significant effect on the distribution of Diamesa larvae. This is in agreement with Robinson et al. (2001) and Uehlinger et al. (2010) who did not detect a correlation of food availability with the occurrence of high alpine benthic species, which is in contrast with Brennan et al. (1977). Our findings suggest that the distribution of chironomid larvae in highly glaciated alpine streams seems to be random and not primarily depending on the small-scale living conditions in the stream. 

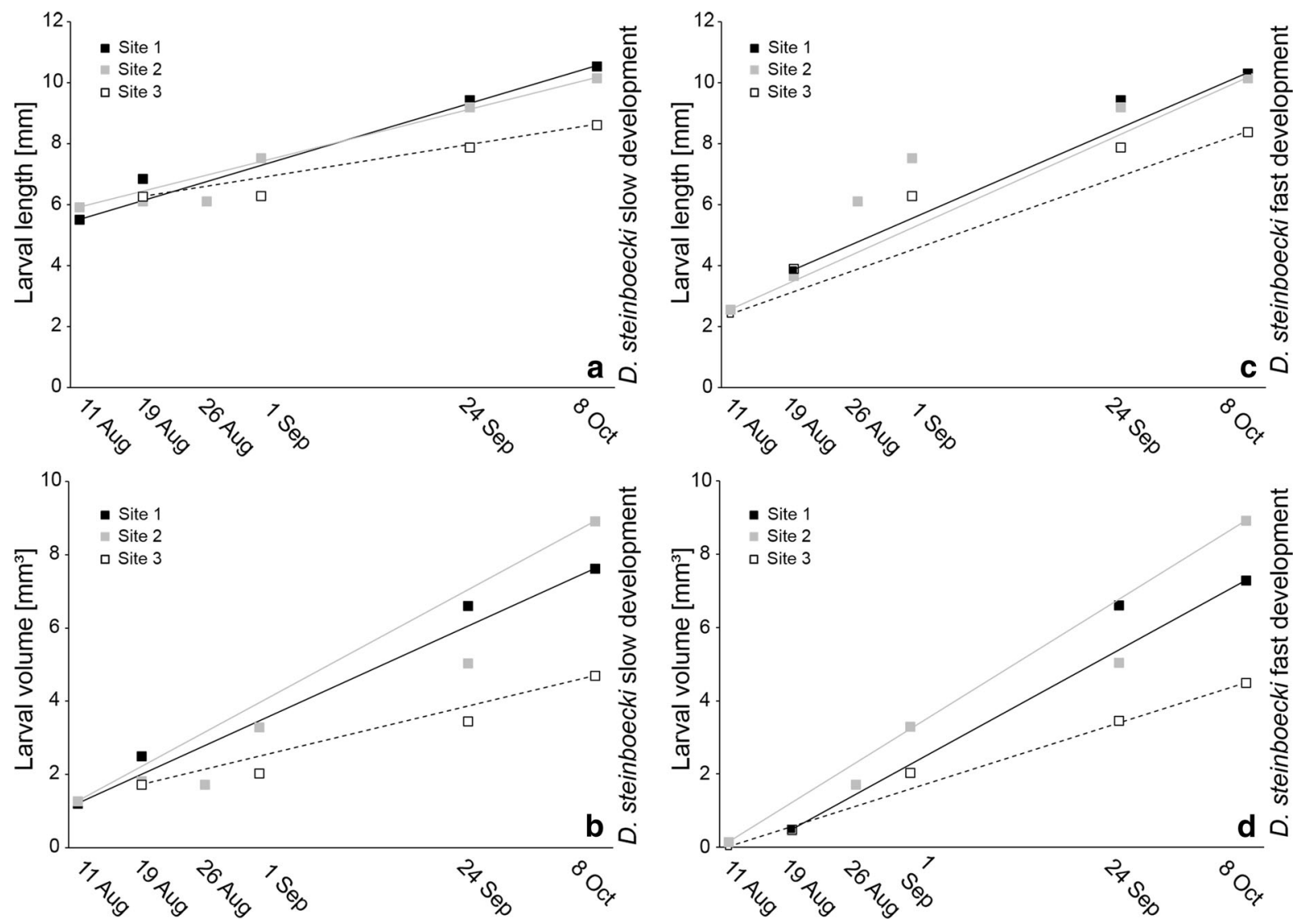

Fig. 9 Slow development of Diamesa steinboecki on the left: means of larval length (a) and larval volume (b) with growth rates (site 1: solid black line, site 2: solid grey line, site 3: dashed

right: means of L2 (sampling 1), L3 (sampling 2) and L4 (sampling 3-6) of larval length (c) and larval volume (d) with growth rates (site 1: solid black line, site 2: solid grey line, site 3 : dashed black line)

Table 2 Growth rates of Diamesa cinerella and Diamesa steinboecki for slow and fast developments, displaying the gains of larval length $\left(\mathrm{G}_{\text {length }}\right)$ and larval volume $\left(\mathrm{G}_{\text {volume }}\right)$ per day

\begin{tabular}{|c|c|c|c|c|c|c|c|}
\hline \multirow[t]{2}{*}{ Growth rates } & \multicolumn{3}{|c|}{ Diamesa cinerella } & \multicolumn{3}{|c|}{ Diamesa steinboecki } & \\
\hline & Site1 & Site 2 & Site 3 & Site1 & Site 2 & Site 3 & \\
\hline $\mathrm{G}_{\text {length }}(\mathrm{mm} /$ day $)$ & 0.064 & 0.096 & 0.065 & 0.083 & 0.072 & 0.047 & Slow development \\
\hline $\mathrm{G}_{\text {volume }}\left(\mathrm{mm}^{3} / \mathrm{d}\right)$ & 0.145 & 0.153 & 0.059 & 0.105 & 0.138 & 0.006 & \\
\hline $\mathrm{G}_{\text {length }}(\mathrm{mm} /$ day $)$ & 0.146 & 0.149 & 0.113 & 0.129 & 0.131 & 0.103 & Fast development \\
\hline $\mathrm{G}_{\text {volume }}\left(\mathrm{mm}^{3} /\right.$ day $)$ & 0.199 & 0.176 & 0.094 & 0.136 & 0.151 & 0.077 & \\
\hline
\end{tabular}

Food availability and not temperature limits larval growth

Larval development did not differ significantly between sampling sites, although site 1 was still covered by the glacier in autumn 2014 and got ice-free during spring/summer 2015, only some months before initial sampling. Due to the high proportion of L4 larvae as well as the presence of pupae towards October, Diamesa cinerella and Diamesa steinboecki are obviously able to finish their aquatic life stages within 1 year and are at least univoltine. Presence of L1 and L2 larvae at the last two sampling dates indicate a summer generation of adult insects who 
mated and were capable of laying eggs during August/ early September, implicating the possibility of a bivoltine life cycle.

Despite the very low water temperatures, both development scenarios are reasonable. Nolte \& Hoffmann (1992) published a fast life cycle of Diamesa incallida (39-43 days) at relatively low water temperatures (about $8^{\circ} \mathrm{C}$ ). Hannesdottir et al. (2012) report on bivoltine life cycles of two Eukiefferiella (Diptera, Chironomidae) species at the same temperature range. In temperate regions, chironomids show rapid development patterns (about 15 days) at their environmental optima (Danks, 2006). Highly adapted species from extreme habitats (e.g., temporary waterbodies) especially can follow fast development strategies (Danks, 2006). Among others, Niedrist \& Füreder (2016) show the cold hardiness of Diamesa species allowing for a successful colonization of the uppermost stream reaches of highly glaciated rivers (see also Milner \& Petts, 1994; Marziali \& Rossaro, 2013). The harsh abiotic conditions of kryal headwaters hit the environmental optima of highly cold adapted Diamesinae and favour their existences. Therefore, univoltinism or even bivoltinism is feasible, although previously undocumented at such low water temperatures. As our samples are snapshots of the life cycles, further investigations following the larval development in these high alpine headwaters, especially during the winter season, are crucial.

Our larvae reached comparable or bigger sizes as previously published. Rossaro \& Lencioni (2015a) state a mean body length of L4 Diamesa cinerella of about $11.2 \mathrm{~mm}$ which is reached by our larvae at site 1 (mean of $11.06 \mathrm{~mm}$ ) and site 2 (mean of $11.03 \mathrm{~mm}$ ). Larvae from site 3 were noticeably smaller (mean of $8.38 \mathrm{~mm}$ ). Diamesa steinboecki larvae from our samples were, however, considerably longer than published by Rossaro \& Lencioni (2015a). D. steinboecki reached mean lengths of $10.54 \mathrm{~mm}$ (site 1), $10.17 \mathrm{~mm}$ (site 2) and $8.64 \mathrm{~mm}$ (site 3), compared to mean body lengths of about $5.1 \mathrm{~mm}$ measured by Rossaro \& Lencioni (2015a).

The decrease of L4 head capsule size, larval length and volume (statistically significant for $D$. cinerella) within about 100 metres of flow, despite increasing distance from the glacier and increasing temperature was unexpected and is contrary to previously published studies. Huryn \& Wallace (1986) studied the development of chironomid larvae at $2.3^{\circ} \mathrm{C}$ and did not register any growth of the chironomid species, but recorded weight loss as the observed larvae stopped feeding. In many laboratory experiments, increased water temperature, compared with the control conditions, positively influenced the larval growth of mayflies, stoneflies or caddisflies leading to the increased larval sizes and/or faster larval development due to an accelerated metabolism (e.g., Brittain, 1983; Corkum \& Hanes, 1991; Frouz et al., 2002; Wagner, 2005). This relation was also observed for chironomids (Konstantinov, 1958; Nebecker, 1973; Nolte \& Hofmann, 1992; Reynolds \& Benke, 2005; Walther et al., 2006; Bouchard \& Ferrington, 2009). Some authors studied the influence of food availability or food quality on the growth and size of chironomid larvae but found the water temperature to be the limiting factor (Bouchard \& Ferrington, 2009; Hannesdottir et al., 2012). However, there are studies underlining the importance of nutrient availability or food quality on the benthic larval size and growth (Oliver, 1971; Mackey, 1977; Menzie, 1981; Davis et al., 2010). Tronstad et al. (2010) report on growth rates of chironomid larvae in natural streams and their dependency on the available nutrients. Stanko-Mishic et al. (1999) show the significance of habitat quality accompanying with nutrient availability and particle size for chironomid larval growth. Thereby the usability of the benthic organic matter was even more important than the total amount of organic material for the benthic invertebrates. As food availability is the only reasonable explanation for the found size patterns in the highly glaciated stream sites, our results attribute nutrients a great importance for benthic larval size in alpine headwaters.

Hydrurus foetidus proved to be a suitable habitat and food source for (high alpine) benthic insects (Knownacka \& Knownacki, 1971). We showed that the Crysophyceae acts like a fertilizer in the desert like environment of highly glaciated headwaters on chironomid larval size. Especially Diamesa cinerella larvae seem to benefit from the presence of the algal mats. This is particularly apparent at the slow development pattern; the initially bigger larvae at site $1 \mathrm{can}$ only be explained by the high availability of benthic organic matter throughout the sampling. As the food availability at site 2 increased throughout the observed period, larval length and volume is increasing, too, resulting in very high growth rates. At the end of our sampling period, L4 larvae from site 2 caught up in 
length and volume compared to larvae of site 1. Larvae from site 3, on the other hand, did not experience such a growth spurt, as nutrient availability was on a significantly lower level throughout the sampling, compared to the other two sites. D. steinboecki seems to be more robust towards low nutrient concentrations. However, with ongoing time, larvae at the two uppermost sites grew bigger also resulting in higher larval sizes closer to the glacier. Our results go along with Niedrist (2017) who show that Diamesa larval size is generally increasing with increasing environmental harshness. Bigger larvae are obviously fitter and better able to resist the harsh living conditions of highly glaciated, alpine streams.

\section{Conclusion}

This is the first study investigating narrow spatial and temporal patterns on species composition, growth and development in a kryal headwater. The considerable differences in size and volume of the chironomid larvae within only $100 \mathrm{~m}$ of flow were unexpected. However, the observed larval size patterns show the efficiency of alpine chironomid species. Despite the very low water temperatures coinciding with a presumed slow metabolism, the Diamesa larvae can benefit from enhanced food availability, expressed by significantly increased growth. Furthermore, this is the first report of a univoltine life cycle in a highly glaciated aquatic ecosystem. Our findings are supported by Niedrist \& Füreder (2017) who also found Hydrurus foetidus to be an important nutrient source for Diamesa larvae in several glaciated streams. Therefore, the unexpected increases of larval length and volume towards the glacier in our study, despite the significantly colder water temperatures, can reasonably be explained by the presence of Hydrurus foetidus. Food availability and not water temperature seems to be the limiting factor for larval size in this harsh freshwater ecosystem. As the observed algal blooms were the highest at site 1 , stream stretches directly located at the glacier snouts can be more productive than previously assumed.

Due to the relatively short sampling period, the results depict an important snapshot of larval development and growth from one stream. Unfortunately, an alternative laboratory experiment, additionally testing the influence of various abiotic drivers on the larval growth of the two investigated Diamesa species is, due to the extreme conditions, not feasible. A simulation of the harsh environmental conditions with water temperatures close to $0^{\circ} \mathrm{C}$, high turbidity and low channel stability due to strongly fluctuating discharges, for several weeks, is impossible. Therefore, larval growth and development in these aquatic ecosystems can only be followed by regular sampling. With our sampling effort, we were able to conclude on a remarkable larval growth and development in an extreme environment. Niedrist (2017) report a similar, general trend of larger chironomid larvae with the increasing environmental harshness, confirming our findings.

Consequently, the harsh environmental conditions of high alpine, kryal streams may exclude many taxa but favour the occurrence of highly adapted chironomid species. When their essential needs are guaranteed (nutrient availability and quality), these species can reach unexpectedly large larval sizes, resulting in an amplified storage of mainly autochthonous organic matter in the ecosystem, enriching the stream food chain at the initial links.

Acknowledgements Open access funding provided by University of Innsbruck and Medical University of Innsbruck. We thank the Hohe Tauern National Park and Land Tirol for the financial support within the project "Gletschertod und Gewässergeburt" (project leader L.F.) and the University of Innsbruck for providing S.A.S. the Ph.D. student grant, as this work is part of his Ph.D. thesis. Furthermore, we thank Saskia Amann, Brigitte Hechenblaickner and Bernhard Kofler for their help in the field.

Open Access This article is distributed under the terms of the Creative Commons Attribution 4.0 International License (http:// creativecommons.org/licenses/by/4.0/), which permits unrestricted use, distribution, and reproduction in any medium, provided you give appropriate credit to the original author(s) and the source, provide a link to the Creative Commons license, and indicate if changes were made.

\section{References}

Beracko, P., A. Kusnirova, M. Partlova \& J. Cicekova, 2016. Community structure, life histories and secondary production of stoneflies in two small mountain streams with different degree of forest cover. Journal of Limnology 75: 169-179.

Bouchard, R. W. \& L. C. Ferrington, 2009. Winter growth, development, and emergence of Diamesa mendotae 
(Diptera, Chironomid) in Minnesota streams. Physiological Ecology 38: 250-259.

Brennan, A., A. J. McLachlan \& R. S. Wotton, 1977. Particulate material and midge larvae (Chironomidae: Dipetra) in an upland river. Hydrobiologia 59: 67-73.

Brittain, J. E., 1983. The influence of temperature on nymphal growth rates in mountain stoneflies (Plecoptera). Ecology 64: 440-446.

Brittain, J. E. \& A. M. Milner, 2001. Ecology of glacier-fed rivers: current status and concepts. Freshwater Biology 46: 1571-1578.

Brittain, J. E., S. J. Saltveit, E. Castella, J. Bogen, T. E. Bonsnes, I. Blakar, T. Bremnes, I. Haug \& G. Velle, 2001. The macroinvertebrate communities of two contrasting glacial rivers in relation to environmental variables. Freshwater Biology 46: 1723-1736.

Brown, L. E., D. M. Hannah \& A. M. Milner, 2007. Vulnerability of alpine stream biodiversity to shrinking glaciers and snowpacks. Global Change Biology 13: 958-966.

Brown, L. E., A. M. Milner \& D. M. Hannah, 2010. Predicting river ecosystem response to glacial meltwater dynamics: a case study of quantitative water sourcing and glaciality index approaches. Aquatic Sciences 72: 325-334.

Brown, L. E., N. E. Dickson, J. L. Carrivick \& L. Füreder, 2015. Alpine river ecosystem response to glacial and anthropogenic flow pulses. Freshwater Science 34: 1201-1215.

Carlos, I. M. \& K. P. Puliafico, 2016. Life cycles of dominant mayflies (Ephemeropetera) on a torrent of the high Bolivian Andes. Revista De Biologica Tropical 64: 291-303.

Corkum, L. D. \& E. C. Hanes, 1991. Effects of temperature and photoperiod on larval size and survivorship of a burrowing mayfly (Ephemeroptera, Ephemeridae). Canadian Journal of Zoology 70: 256-263.

Daly, H. V., 1985. Insect morphometrics. Annual Review of Entomology 30: 415-438.

Danks, H. V., 2006. Short life cycles in insects and mites. Canadian Entomologist 138: 407-463.

Danks, H. V., 2007. How aquatic insects live in cold climates. Canadian Entomologist 139: 443-471.

Davis, J., A. D. Rosemond, S. L. Eggert, W. F. Cross \& J. B. Wallace, 2010. Nutrient enrichment differentially affects body sizes of primary consumers and predators in a detritus-based stream. Limnology and Oceanography 55: 2305-2316.

Dobrin, M. \& D. J. Giberson, 2003. Life history and production of mayflies, stoneflies, and caddiesflies (Ephemeroptera, Plecoptera, and Trichoptera) in a spring-fed stream in Prince Edward Island, Canada: evidence for population asynchrony in spring habitats? Canadian Journal of Zoology 81: 1083-1095.

Elliott, J. M., 2013. Contrasting dynamics from egg to adult in the life cycle of summer and overwintering generations of Baetis rhodani in a small stream. Freshwater Biology 58: 866-879.

Erba, S., L. Melissano \& A. Buffagni, 2003. Life cycles of Baetidae (Insecta. Ephemeroptera) in a North Italian Prealpine stream. In Gaino, E. (ed), Research Update on Ephemeroptera and Plecoptera. University of Perugia, Perugia: $177-186$.

Finn, D. S. \& N. L. Poff, 2008. Emergence and flight activity of alpine stream insects on 2 years with contrasting winter snowpack. Arctic, Antarctic and Alpine Research 40: 638-646.

Finn, D. S., K. Räsänen \& C. T. Robinson, 2010. Physical and biological changes to a lengthening stream gradient following a decade of rapid glacial recession. Global Change Biology 16: 3314-3326.

Frouz, J., A. Arshad \& R. J. Lobinske, 2002. Influence of temperature on development rate, wing length, and larval head capsule size of pestiferous midge Chironomus crassicaudatus (Diptera: Chironomidae). Journal of Economic Entomology 95: 699-705.

Füreder, L., 1999. High Alpine streams: cold habitat for insect Larvae. In: Margesin, R. \& F. Schinner (eds), Cold Adapted Organisms. Ecology, Physiology, Enzymology and Molecular Biology. Springer Verlag, Berlin.

Füreder, L., 2007. Life at the edge: habitat condition and bottom Fauna of Alpine running waters. International Review of Hydrobiology 92: 491-513.

Füreder, L., M. Wallinger \& R. Burger, 2005. Longitudinal and seasonal pattern of insect emergence in alpine streams. Aquatic Ecology 39: 67-78.

Hannesdottir, E. R., G. M. Gislason \& J. S. Olafsson, 2012. Life cycles of Eukiefferiella claripennies (Lundbeck 1898) and Eukiefferiella minor (Edwards 1929) (Diptera: Cironomidae) in spring-fed streams of different temperatures with reference to climate change. Fauna Norvegica 31: 35-46.

Hooper, H. L., R. M. Sibly, T. H. Hutchinson \& S. J. Maund, 2003. The influence of larval density, food availability and habitat longevity on the life history and population growth rate of the midge Chironomus riparius. OIKOS 102: 515-524.

Huryn, A. D. \& B. J. Wallace, 1986. A method for obtaining in situ growth rates of larval Chironomidae (Diptera) and its application to studies of secondary production. Limnology and Oceanography 31: 216-222.

Jacobsen, D. \& O. Dangles, 2012. Environmental harshness and global richness patterns in glacier-fed streams. Global Ecology and Biogeography 21: 647-656.

Janecek, F. R., 1998. Fauna aquatica Austriaca, taxonomie und ökologie aquatischer wirbelloser organismen, Diptera: Chironomidae (Zuckmücken). Universität für Bodenkultur, Abteilung Hydrobiologie, Wien.

Knownacka, M. \& A. Knowancki, 1972. Vertical distribution of zoocenoses in the streams of the Tatra, Caucasus and Balkans Mts. Verhandlungen der Internationalen Vereinigung für Theoretische und Angewandte Limnologie 18: 742-750.

Konstantinov, A. S., 1958. The effect of temperature on growth rate and development of chironomid larvae. Doklady Akademii Nauk SSSR Biological Sciences 120: 495-498.

Langton, P. H., 1991. A key to pupal exuviae of West Palaearctic Chironomidae. Huntingdon, Cambridgeshire: 386.

Lods-Crozet, B., E. Castella, D. Cambin, C. Ilg, S. Knispel \& H. Mayor-Simeant, 2001. Macroinvertebrate community structure in relation to environmental variables in a Swiss glacial stream. Freshwater Biology 46: 1641-1661.

Mackey, A. P., 1977. Growth and development of larval Chironomidae. Oikos 28: 270-275.

Marziali, L. \& B. Rossaro, 2013. Response of chironomid species (Diptera, Chironomidae) to water temperature: effects 
on species distribution in specific habitats. Journal of Entomological and Acarological Research 45: 73-89.

Menzie, C. A., 1981. Production ecology of Cricotopus sylvestris (Fabricius) (Diptera: Chironomidae) in a shallow estuarine cove. Limnology and Oceanography 26: 467-481.

Milner, A. M. \& G. E. Petts, 1994. Glacial rivers: physical habitat and ecology. Freshwater Biology 32: 295-307.

Nebecker, A. V., 1973. Temperature requirements and life cycle of the midge Tanytarsus dissimilis (Diptera: Chironomidae). Journal of Kansas Entomological Society 46: 160-165.

Niedrist, G. H., 2017. Feeding ecology of alpine chironomids. Basic principles, underlying mechanism and future prospects under climate change conditions. Ph.D. thesis, University of Innsbruck, Innsbruck, Austria: 165.

Niedrist, G. H. \& L. Füreder, 2016. Towards a definition of environmental niches in alpine streams by employing chironomid species preferences. Hydrobiologia 781: 143-160.

Niedrist, G. H. \& L. Füreder, 2017. Trophic ecology of alpine stream invertebrates: current status and future research needs. Freshwater Science 36: 466-478.

Nolte, U., 1990. Chironomid biomass determination from larval shape. Freshwater Biology 24: 443-451.

Nolte, U. \& T. Hoffmann, 1992. Fast life in cold water: Diamesa incallida (Chironomidae). Ecography 15: 25-30.

Oliver, D. R., 1971. Life history of the Chironomidae. Annual Review of Entomology 16: 211-230.

Resh, V. H. \& D. M. Rosenberg, 2010. Recent trends in lifehistory research on benthic macroinvertebrates. Journal of the North American Benthological Society 29: 207-219.

Reynolds, S. K. \& A. C. Benke, 2005. Temperature-dependent growth rates of larval midges (Diptera: Chionomidae) from a southeastern US stream. Hydrobiologia 544: 69-75.

Robinson, C. T., U. Uehlinger \& M. Hieber, 2001. Spatiotemporal variation in macroinvertebrate assemblages of glacial streams in the Swiss Alps. Freshwater Biology 46: 1663-1672.

Robinson, C. T., C. Thompson \& M. Freestone, 2014. Ecosystem development of streams lengthened by rapid glacial recession. Fundamental and Applied Limnology 185: 235-246.

Robinson, C. T., R. Alther, M. Leys, S. Moran \& C. Thompson, 2015. A note on the trophic structure of alpine streams in the Wind River Mountains, Wyoming, USA. Fundamental and Applied Limnology 187: 43-54.

Romanovsky, Y. E. \& L. V. Polishchuk, 1982. A theoretical approach to calculation of secondary production at the population level. Internationale Revue der gesamten Hydrobiologie 67: 341-359.

Rossaro, B. \& V. Lencioni, 2015a. A key to larvae of species belonging to the genus Diamesa from Alps and Apennines (Italy). European Journal of Environmental Sciences 5: 62-79.
Rossaro, B. \& V. Lencioni, 2015b. A key to larvae of Diamesa Meigen, 1835 (Diptera: Chironomidae), well known as adult males and pupae from Alps (Europe). Journal of Entomological and Acarological Research 47: 123-138.

Rossaro, B., M. Montagna \& V. Lencioni, 2016. Environmental traits affect chironomid communities in glacial areas of the Southern Alps: evidence from a long-lasting case study. Insect Conservation and Diversity 9: 192-201.

Sand, K. \& J. E. Brittain, 2009. Life cycle shifts in Baetis rhodani (Ephemerotera) in the Norwegian mountains. Aquatic Insects 31: 283-291.

Schmid, P.E., 1993. Wasser und Abwasser. A key to the larval Chironomidae and their instars from Austrian Danube region streams and rivers with particular reference to a numerical taxonomic approach. Federal Institute for Water Quality Wien; Supplementary 3/93: 514.

Stanko-Mishic, S., J. K. Cooper \& S. Pamela, 1999. Manipulation of habitat quality: effects on chironomid life history traits. Freshwater Biology 41: 719-727.

Steffan, A. W., 1971. Chironomid (Diptera) biocoenoses in Scandinavian glacier brooks. The Canadian Entomologist 103: 477-486.

Sweeney, B. W., R. L. Vannote \& P. J. Dodds, 1986. Effects of temperature and food quality on growth and development of a mayfly, Leptophlebia intermedia. Canadian Journal of Fisheries and Aquatic Sciences 43: 12-18.

Tronstad, L. M., B. P. Tronstad \& A. C. Benke, 2010. Growth rates of chironomids collected from an ephemeral floodplain wetland. Wetlands 30: 827-831.

Uehlinger, U., F. Malard \& J. V. Ward, 2003. Thermal patterns in the surface waters of a glacial river corridor (Val Roseg, Switzerland). Freshwater Biology 48: 284-300.

Uehlinger, U., C. T. Robinson, M. Hieber \& R. Zah, 2010. The physico-chemical habitat template for periphyton in alpine glacial streams under a changing climate. Hydrobiologia 657: 107-121.

Vannote, R. L., G. W. Minshall, K. W. Cummins, J. R. Sedell \& C. E. Cushing, 1980. The river continuum concept. Canadian Journal of Fisheries and Aquatic Sciences 37: 130-177.

Wagner, R., 2005. The influence of stream water temperature on size and weight of caddisflies (Insects, Trichoptera) along the Breitenbach 1983-1991. Archiv für Hydrobiologie 163: 65-79.

Walker, I. R., 1987. Chironomidae (Diptera) in palaeoecology. Quaternary Science Reviews 6: 29-40.

Walther, A. D., M. R. Whiles, M. B. Flinn \& D. W. Butler, 2006. Assemblage-level estimation of nontanypodinae chironomid growth and production in a southern Illinois stream. Journal of the North American Benthological Society 25: 444-452.

Ward, J. V., 1994. Ecology of alpine streams. Freshwater Biology 32: 277-294. 